\title{
Review of caesarean sections at full dilatation
}

\section{Vijaya Monish Babre*, Kirti Rajesh Bendre, Geeta Niyogi}

Department of Obstetrics and Gynecology, K. J. Somaiya Medical College, Sion, Mumbai, Maharashtra, India

Received: 28 March 2017

Accepted: 27 April 2017

\section{*Correspondence:}

Dr. Vijaya Monish Babre,

E-mail: drvbabre@gmail.com

Copyright: (c) the author(s), publisher and licensee Medip Academy. This is an open-access article distributed under the terms of the Creative Commons Attribution Non-Commercial License, which permits unrestricted non-commercial use, distribution, and reproduction in any medium, provided the original work is properly cited.

\section{ABSTRACT}

Background: To study indications of second stage caesarean section. To study intraoperative and postoperative complications. To review maternal and perinatal outcome.

Methods: This retrospective study was conducted at a tertiary teaching Institute. All second stage caesarean sections performed between a period 2008 to 2012 were analysed in terms of duration of $2^{\text {nd }}$ stage of labour, instrumentation attempted prior to caesarean section, indication of caesarean-section, Intraoperative complications, maternal and perinatal outcome.

Results: During the study period 2760, caesarean sections were performed out of them 61 were 2 nd stage caesarean section. Out of 61 Caeserean 14 were given prior instrumental trial, followed by 2nd stage caesarean section. Intraoperative complications were higher in terms of blood loss, primary PPH, extension of uterine incision, in one case bladder injury was noticed. Patwardhan method was used in $23 \%$ cases for delivery deeply engaged head. Atonic PPH was seen in $11.5 \%$ of patiants.3.3\% of patients had extension of uterine incision. $54 \%$ baby's required NICU care. Increased incidence of post-operative febrile illness and wound infection were noted.

Conclusions: Caeseraen section in the $2^{\text {nd }}$ stage of labour is associated with significantly increased maternal morbidity. Neonatal morbidity and mortality also increases. A proper judgement is required by a skilled obstetrician to take a decision for instrumental delivery or ceaseraen section at full cervical dilatation.

Keywords: Caesarean section, Intraoperative complications, Maternal outcome, Patwardhan method, Perinatal outcome

\section{INTRODUCTION}

The incidence of caesarean section has risen steadily in last two decades. The high rate of caesarean section is now regarded as a major public health problem. Caesarean section at full dilatation is associated with high maternal and fetal morbidity. ${ }^{1,2}$

The objective of the study was to study indications of second stage caesarean section. To study intra operative complications like PPH, extension of incision, intra operative blood transfusion, methods of delivery of head of baby. To study post-operative maternal complications like wound infection, febrile illness. To study fetal complications like NICU admission and mortality

\section{METHODS}

This retrospective study was conducted at tertiary teaching institute in Mumbai over last 5 years. All second stage caesarean sections performed between a period of 2008 to 2012 were studied. Total number of deliveries during this period was 9194. Among these 2760 were delivered by caesarean section out of this 61caesarean section were performed in second stage of labour. These second stage caesarean section were analyzed in terms of 
indications of 2nd stage caesarean section. Prior instrumentation before caesarean section, intra operative complications and postoperative complications like febrile illness, paralytic ileus, wound infection. Neonatal morbidity and mortality.

\section{RESULTS}

In study that based on sample of 61 (2.21\%). Primigravida were $45(74 \%)$ and Multigravida were 16 (26\%).

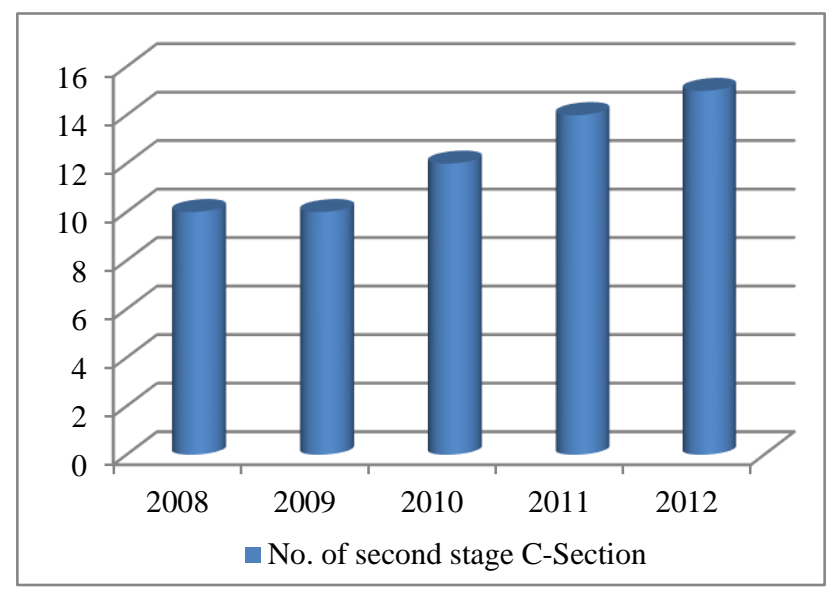

Figure 1: Number of second stage C-Section performed in last 5 years.

Figure 1 shows number of second stage C-sections were increased over 5 year.

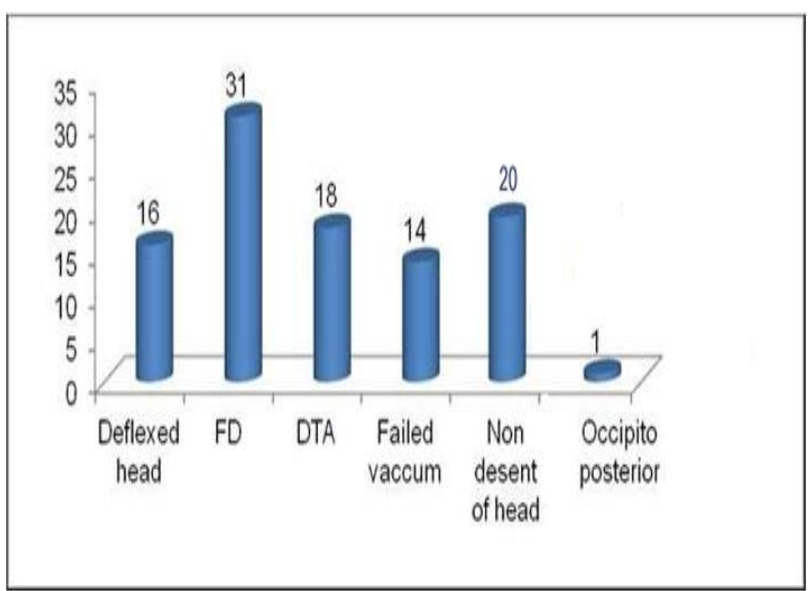

*Percentages may exceed $100 \%$ as multiple indications present

Figure 2: Indications of 2nd Stage caesarean section.

Most common indication of second stage of C-section in study group were fetal distress due to non-descent of head due to cephalopelvic disproportion and deep transverse arrest.

Table 1 shows different techniques of delivery of deeply engaged head.
Table 1: Technique of delivery of deeply engaged head.

\begin{tabular}{|ll|l|}
\hline & Count & Column N \% \\
\hline Baby delivered by Vx & 41 & 67.2 \\
\hline Patwardhan & 14 & 23.0 \\
\hline Push Method & 6 & 9.8 \\
\hline Total & 61 & 100.0 \\
\hline
\end{tabular}

Table 2: Intraoperative complications.

\begin{tabular}{|ll|}
\hline A tonic PPH & $11.5 \%$ (No. of patients 7$)$ \\
\hline Blood Transfusion & $8.2 \%$ (No. of patients 5) \\
\hline $\begin{array}{l}\text { Extension of uterine } \\
\text { incision }\end{array}$ & $3.3 \%$ (No. of patients 2$)$ \\
\hline Injury to bladder & $1.6 \%$ (No. of patient 1$)$ \\
\hline
\end{tabular}

Table 2 shows intra operative complications. Vacuum application were tried in $23 \%$ of patient's prior caesarean section but failed and required emergency caesarean section. Atonic PPH was observed in $11.5 \%$ of patients due to prolonged second stage of labor, which was medically managed. Extension of uterine incision were observed in $3.3 \%$ cases due to operative difficulty in delivery of deeply engaged head and thinned out oedematous lower segment. Increased incidence of blood transfusion $8.2 \%$ due to atonic PPH, excessive bleeding due to extension of uterine incision. In one case injury to bladder was observed with history of LSCS. Postoperative complication like febrile illness were observed in $19.7 \%$ of cases due to prolonged second stage of labour, ruptured of membrane, multiple per vaginal examination, instrumentation attempted prior to LSCS. Wound infection was observed in $8.2 \%$ cases.

Table 3: Postoperative complications.

\begin{tabular}{|ll|}
\hline Postoperative complications & No. of patients (\%) \\
\hline Febrile Illness & $12(19.7)$ \\
\hline Wound Infection & $5(8.2)$ \\
\hline
\end{tabular}

Table 3 shows post-operative complications. NICU admission were observed in $54.1 \%$ babies due to birth asphyxia, sepsis, seizure, need for ventilation.

\section{DISCUSSION}

During the five year study period 2760/9194 of babies were delivered by C-Section; of these $(n=61) 2.21 \% \mathrm{C}$ Sections were performed at full dilatation.In our study the incidence of $2^{\text {nd }}$ stage cesarean sections is more seen in primigravida $(74 \%)$ than in multigravida $(26 \%)$ due to mild to moderate cephalopelvic disproportion, rigid perineum, lack of experience of previous labour in primigravida women same results were found in study done by Feinstein, et al. ${ }^{3,4}$ The rising incidence of second stage C-Section was observed over last 5 years (Figure 1). ${ }^{2}$ Most common indications for $2^{\text {nd }}$ stage $\mathrm{C}$-section was fetal distress followed by deep transverse arrest (DTA) (Figure 2). Vacuum was applied in $23 \%$ of cases but 
failed and required $2^{\text {nd }}$ stage $\mathrm{C}$-Section. As the duration for second stage increases, there would be more difficulties due to oedematous lower segment, overstretched and thinned out lower segment and more impaction of presenting part in pelvis. Operative time was also increased due to difficulty of delivery of deeply engaged head. Increased incidence of atonic postpartum hemorrhage due to prolonged 2nd stage of labour. ${ }^{5}$ In our study, atonic PPH was observed in $11.5 \%$ of patients and extension of uterine incision was found $3.3 \%$ of patients. As compare to study conducted by Shahla Baloch, et al was observed $12.5 \% \mathrm{PPH}$ and $5.4 \%$ extension of wound. ${ }^{3}$ Extension of uterine incision was observed in few cases due to manipulation of baby at the time of delivery. Bladder injury was observed in one case with previous one LSCS. Increased incidence of blood transfusion in study group due to postpartum haemorrage.

Delivery of deeply engaged head is challenge to obstetrician, this can be done by various methods as shown in Table 1 Vertex method, pull method i.e. Patwardhan's Method, push method in this method head is pushed vaginally and then deliver head through uterine incision. In study group deeply engaged head delivered by vertex method were $67.2 \%$, Patwardhan method were $23 \%$ and by push method 9.8\%.6,7 Post-operative complications like hematuria, febrile illness $19.7 \%$, paralytic ileus $13.3 \%$ patients, wound infection $8.2 \%$ were more in study group. Study conducted by Shahla Baloch, et al shows similar results. ${ }^{3}$ Future VBAC chances are also reduced due to maternal morbidity associated with 2nd stage C-Section. NICU admissions were significantly high due to birth asphyxia in study group.

\section{CONCLUSION}

Caesarean section in the second stage of labour is associated with significantly increased maternal and neonatal morbidity as well as increased neonatal mortality. A proper judgment and skilled obstetrician is required to perform second stage $\mathrm{C}$ - Section.

Funding: No funding sources

Conflict of interest: None declared

Ethical approval: The study was approved by the Institutional Ethics Committee

\section{REFERENCES}

1. Panday GV. Second Stage caesarean section at a tertiary centre in South Africa, Journal of MaternalFetal Neonat medic. 2010;23(10)1151-1155.

2. Unterscheider J, McMenamin M, Cullinane F. Rising rates of caserean deliveries at full cervical dilatation: A concerning trend. Eur J Obstet Gynaecol reprod boil. 2011;157;141-4.

3. Baloch S, Khaskheli M. Frequency of Second stage Intervention and its outcome in relations with instrumental vaginal delivery versus cesarean section. J Ayub Med Coll Abbottabad. 2008;20(1):87-90.

4. Feinstein U, Sheiner E, Levy A, Hallak M, Mazor M. Risk factor for arrest of descent during the second stage of labour. Int J Gynaecol Obstet. 2002;77(1):714.

5. McKelvey A, Ashe R. Caesarean section in the second stage of labour : a retrospective review of Obstetrics setting and morbidity. J Obstet Gynaecol, 2010;30(3):264-7.

6. The Caeserean birth, FOGSI, $1^{\text {st }}$ edition 2004;131-4.

7. Indian contribution to obstetrics \& Gynaecology. J Obstetrics Gyaenacol Ind. 2012;62(4);384-5.

Cite this article as: Babre VM, Bendre KR, Niyogi $\mathrm{G}$. Review of caesarean sections at full dilatation. Int J Reprod Contracept Obstet Gynecol 2017;6:2491-3. 